\title{
MIDIALIVRISMO E NARRATIVAS HEGEMÔNICAS - EMERGÊNCIA E CAPTURA DE UMA MÍDIA DA MULTIDÃO
}

\section{ARTIGO ORIGINAL}

CARVALHO, Antonio Donizeti de ${ }^{1}$

COSTA, Rogério da ${ }^{2}$

CARVALHO, Antonio Donizeti de. COSTA, Rogério da. Midialivrismo e narrativas hegemônicas - Emergência e captura de uma mídia da multidão. Revista Científica Multidisciplinar Núcleo do Conhecimento. Ano 04, Ed. 10, Vol. 03, pp. 143158. Outubro de 2019. ISSN: 2448-0959, Link de acesso: https://www.nucleodoconhecimento.com.br/comunicacao/midialivrismo-enarrativas

\section{RESUMO}

Este trabalho examina processos emergentes no campo comunicacional e as narrativas independentes implementadas pelos novos autores do midialivrismo em oposição às narrativas empregadas pelos tradicionais emissores dos meios de comunicação instituídos. Para tanto, lança-se à abordagem de acontecimentos recentes no Brasil como, por exemplo, as manifestações de rua a partir de junho e julho de 2013, momento em que formas alternativas de informação se evidenciam e interferem nos fluxos de trabalho da mídia tradicional.

1 Doutorado em andamento em Comunicação e Semiótica; Mestrado em Comunicação e Semiótica; Especialização em Globalização e Cultura; Especialização em Marketing e Comunicação; Graduação em comunicação social - jornalismo.

2 Doutorado em História da Filosofia; Mestrado em Filosofia; Especialização em História das Ciências; Especialização em Filosofia Leibniz e o Barroco; Especialização em Filosofia; Graduação em Engenharia de Sistemas e Computação. 
Palavras-chave: Midialivrismo, mídias tradicionais, manifestações, narrativas do acontecimento.

\section{INTRODUÇÃO}

O avanço tecnológico que se vivencia desde os anos 2000, possibilitou o aparecimento de mídias digitais, bem como o contato de indivíduos por redes sociais, permitindo a circulação de produtos simbólicos numa contínua variedade de pautas com uma velocidade acelerada. Além de ter viabilizado o advento de transmissões independentes de características multimídia (mídias da multidão), criou igualmente as condições para a integração dessas às instituições de mídia tradicionais já existentes. A análise da multiplicidade de narrativas, tanto as irradiadas pelos novos atores do midialivrismo quanto as veiculadas pelas empresas de comunicação tradicionais cuja extensão se dilata com os suportes digitais -, compõem o presente objeto de discussão.

As manifestações de rua no Brasil, convocadas pela internet, deflagradas a partir das "Jornadas de junho de 2013", que culminaram nos protestos de 2016 (e em seus desdobramentos políticos), oferecem pano de fundo para a investigação do fenômeno do midiativismo, cujas narrativas se dão na transmissão de dentro do acontecimento, como mídia de contato, em contraste com a cobertura jornalística dos meios estabelecidos. Ademais, tem-se o aparecimento de novos meios, que, articulados entre si e com a lógica do acontecimento, fazem emergir uma infinidade de emissores cuja atuação expõe uma possível fissura no sistema hegemônico de transmissão simbólica, uma vez que se pautam por interesses diversos, e cujas narrativas adquirem a dinâmica do contato.

A reboque dessas transformações, o surgimento de sites independentes de notícias e análises, por irradiarem conteúdos de maneira cooperativa, permite o exercício da crítica uma vez que, nestes, além da possibilidade de outras angulações, comentários acerca da construção da notícia realizada pela grande mídia logram a revelação para o leitor/espectador/internauta dos interesses que norteiam a escolha dos 
enquadramentos ${ }^{[3]}$. Diante dessa dinâmica que se configura, o objeto de pesquisa da área da comunicação se alarga e se complexifica amplamente, cabendo ao pesquisador a observação das múltiplas narrativas que emergem em constante disputa simbólica pela composição daquilo a que se atribuirá o status de verossimilhança. Dado o contexto, as narrativas independentes implementadas pelos novos autores do midialivrismo emergem em oposição às narrativas empregadas pelos tradicionais emissores dos meios de comunicação instituídos - narrativas distintas em torno do mesmo ato.

Destarte, a cobertura de acontecimentos recentes no Brasil, durante e decorrentes das manifestações de rua a partir de junho e julho de 2013 - momento em que formas alternativas de informação se erguem, intensificam-se e passam a interferir nos fluxos de trabalho da mídia tradicional -, oferece-se para análise crítica e para a investigação da especificidade da notícia como estratégia de construção e comunicação do acontecimento, bem como para a análise das relações do jornalismo com as novas tecnologias.

\section{SOB UM NOVO OLHAR}

No prefácio do livro $A$ internet e a rua: ciberativismo e mobilização nas redes sociais, as considerações de Ivana Bentes ilustram a necessidade de um novo olhar para os acontecimentos que se erguem como os novos desafios de pesquisa na Área de comunicação:

No Brasil, capítulo de um livro a ser escrito pelos muitos, a emergência de uma mídia da multidão aponta para um novo momento do midiativismo, encarnado, nos protestos em junho e julho de 2013 pela experiência da Mídia Ninja (Narrativas Independentes Jornalismo e Ação) que cobriu colaborativamente as manifestações em todo o Brasil, "streamando" e produzindo uma experiência catártica de "estar na rua", obtendo picos de 25 mil pessoas online. A Mídia Ninja fez emergir e deu visibilidade ao "pós-telespectador" de uma "pós-TV" nas redes, com manifestantes virtuais que participam ativamente dos protestos/ emissões discutindo, criticando, estimulando, observando e intervindo ativamente nas transmissões em tempo real e se tornando uma

Disponível em: https://www.nucleodoconhecimento.com.br/comunicacao/midialivrismo-e- 
referência por potencializar a emergência de "ninjas" e midialivristas em todo o Brasil.

Indo além do "hackeamento" das narrativas, a Mídia Ninja passou a pautar a mídia corporativa e os telejornais ao filmar e obter as imagens do enfrentamento dos manifestantes com a polícia, a brutalidade e 0 regime de exceção (policiais infiltrados jogando coquetéis Molotov, polícia à paisana se fazendo passar por manifestantes violentos, apagamento e adulteração de provas, criminalização e prisão de midiativistas, estratégias violentas de repressão, gás lacrimogêneo e balas de borracha, etc.). (Malini e Antoun, 2013, p. 15).

Maurizio Lazzarato, em As revoluções do capitalismo, tece uma proposta para se pensar acerca das lutas do século XXI, que devem ser descortinadas não mais por explicações binárias, e sim de maneira dialética. Partindo da noção de público de Gabriel Tarde, sustenta que os corpos e mentes que estão em contato nas ruas são mundos que se tocam pela comunicação e formam, pelo contato, a abertura de "mundos possíveis". Diante disso, as "máquinas de expressão", que pela modulação dos desejos e das mentes produzem a "opinião pública", são os principais instrumentos de captura das atividades de criação e de invenção, ou seja, de mundos possíveis.

Nessas considerações, o autor aborda os acontecimentos em Seattle, em 1999, ocasião em que milhares de manifestantes com motivações e perspectivas políticas distintas se mobilizaram em manifestações contra o encontro da OMC (Organização mundial do Comércio). "Os dias de Seattle foram um verdadeiro acontecimento político que, como todo acontecimento, produziram em primeiro lugar uma transformação da subjetividade, ou seja, da maneira de sentir: não suportamos mais aquilo que suportávamos antes [...]". (Lazzarato, 2006, p. 11). Discorre sobre um "possível" criado a partir desses eventos que diferem dos acontecimentos políticos que perpassaram o século XX. Uma possibilidade anunciada, mas que precisa, conforme enfatiza, ser efetivada. "Limita-se a anunciar que o possível foi criado, que novas possibilidades de vida estão se expressando e que se trata de efetuá-las. A possibilidade de um outro mundo surgiu, mas precisa ser efetuada". (lbid., p. 12).

Disponível em: https://www.nucleodoconhecimento.com.br/comunicacao/midialivrismo-e- 
E é esse possível que poderá se efetivar, e ser transmitido, via as novas e múltiplas narrativas estabelecidas pelo contato "de dentro" do acontecimento, que a narrativa das mídias corporativas vai tentar obstar, pois esse possível, seguindo essa linha, é um processo, imprevisível, constantemente aberto aos riscos que, no entanto, é uma resistência dada em um processo de criação, de transformação do contexto em que se insere. Como afirma Lazzarato:

Os dias de Seattle foram, antes de mais nada, um agenciamento corporal, uma mistura de corpos (com suas ações e paixões), composta de singularidades individuais e coletivas (multiplicidades de indivíduos, de organizações - marxistas, ecologistas, sindicalistas, trotskistas, ativistas de mídia, esotéricos, black blocs) que praticam relações específicas de "cofuncionamento" corporal (diversas maneiras de estar junto, de militar: os sindicalistas não funcionam da mesma maneira que os ativistas de mídia ou os esotéricos). Os dois agenciamentos são, dessa maneira, construídos a partir de relações de poder e de desejo já atualizadas. (Ibid., p. 21).

Durante as coberturas das manifestações brasileiras, eclodidas em junho de 2013, observam-se diferentes narrativas, pontos de vista divergentes sobre os acontecimentos. O coletivo Fora do Eixo, por exemplo, apresentava os fatos "de dentro" e em tempo real, enquanto os veículos de comunicação corporativa (impresso e televisivo) dedicavam-se a um outro enquadramento - e, junto a esse, a construção discursiva para os próprios midiativistas ia paralelamente sendo urdida.

Texto publicado no site do Observatório da imprensa (Comentário para o programa radiofônico do Observatório, 19/08/2013) apresenta o teor do tratamento dedicado pelos órgãos de mídia corporativa, a começar pelo título, "O linchamento da Mídia Ninja":

Algumas das mais prestigiadas cabeças da imprensa têm se empenhado, nos últimos dias, a uma articulada operação com o objetivo de desmoralizar o coletivo de produções culturais chamado Fora do Eixo e, como resultado indireto, demonizar o fenômeno de midiativismo conhecido como Mídia Ninja.

Não se pode dizer que esse movimento seja organizado, da mesma forma como se planeja uma pauta de jornal, mas são fortes as evidências

Disponível em: https://www.nucleodoconhecimento.com.br/comunicacao/midialivrismo-e- 
de uma estratégia comum em suas iniciativas. Há uma urgência na ação de desconstrução da mídia alternativa que nasce em projetos culturais à margem da indústria de comunicação e entretenimento - e os agentes dessa estratégia têm motivos fortes para isso.

Interessante observar que essa operação-desmanche reúne desde os mais ferozes e ruidosos porta-vozes do reacionarismo político até pensadores identificados com correntes vanguardistas, o que compõe um mosaico de discursos que vão dos costumeiros rosnados de blogueiros raivosos até lucubrações mais ou menos sofisticadas de intelectuais sobre o ambiente comunicacional contemporâneo ${ }^{[4]}$.

O próprio título de uma reportagem, por exemplo, publicada na seção “Democratização Comunicação”, no site Pragmatismo Político, já orienta o leitor para um estado de coisas que se esboça no campo da cobertura jornalística dos eventos: "Por que a mídia tradicional tem medo da Mídia Ninja?" [5]. No texto, pode-se apreender a difusão desse tipo de trabalho jornalístico que emerge nas cavidades deixadas pela grande mídia, apesar das atenuações de uma prática em germe, conforme se observa no subtítulo: "Alcance da Mídia Ninja explodiu com os protestos de junho. Entusiastas aplaudem proximidade dos ativistas com acontecimentos, mas analistas ponderam necessidade de contextualizar informação":

[...] O papel de grupos alternativos de comunicação como a Mídia Ninja também podem servir para "oxigenar" a produção de informação do tradicional jornalismo no Brasil, segundo afirma Sylvia Debossan Moretzsohn, professora da Universidade Federal Fluminense no Rio de Janeiro.

"Eu acho que [a Mídia Ninja] vem preencher uma lacuna, sobretudo porque recupera essa reportagem de rua, essa ênfase no que está acontecendo neste momento e ao vivo", exemplifica.

As formas alternativas de informação, como a Mídia Ninja e o site Repórter Brasil, acabam mudando também certos fluxos de trabalho da mídia tradicional, diz a autora do livro Repórter no Volante. "Há um aumento brutal de fontes que querem se apresentar como informação, e é preciso selecionar tudo isso de forma muito mais criteriosa. Os jornalistas continuam tendo esse papel de mediação. Que credibilidade tem a internet, de forma geral? Posso publicar o que eu quiser e depois apagar, como indivíduo. Mas sempre há uma promessa de credibilidade no jornalismo, seja na forma de grandes empresas ou nas formas alternativas", explica a professora da UFF[6]. 
Notadamente, as reivindicações, que num primeiro momento se concentravam nas manifestações contra o aumento das passagens de ônibus, em São Paulo, de $R \$ 3,00$ para $R \$ 3,20$, encampadas pelo MPL (Movimento Passe Livre), se espalharam para várias cidades brasileiras, mobilizando milhares de pessoas sob o escopo, então, de uma multiplicidade de temas. Os manifestantes, dentre outros motivos, saíram às ruas para protestar contra a corrupção, os gastos em grandes eventos internacionais como a Copa do Mundo de 2014, a baixa qualidade e falta de investimentos nos serviços públicos na área da saúde e da educação. A cobertura jornalística realizada pelos jornais e canais de TV tradicionais levou a uma segmentação simbólica desses cidadãos que estavam nas ruas, conforme ilustra o balanço feito em matéria publicada em 27/12/2013, pelo jornal Folha de S. Paulo, "Retrospectiva: Manifestações não foram pelos 20 centavos", em que as "Jornadas" são dispostas em três fases.

[...] É possível distinguir ao menos três fases de protestos. A primeira teve foco na tarifa e reuniu majoritariamente estudantes. A segunda com forte apoio popular e mais efêmera- arrastou multidões contra a baixa qualidade dos serviços públicos, a corrupção, a polícia e tudo o mais.

Por fim, restaram as "manifestações" mais radicais, já sem o apoio da maioria da população, marcadas pela quebradeira dos adeptos da tática "black bloc". Num balanço de "conquistas das ruas" há muito o que enumerar. [...] ${ }^{[7]}$

E é nesse agenciamento - apaziguamento dos corpos - no sentido de dividir de um lado "a multidão pacífica e ordeira" e, do outro, "os mascarados adeptos do vandalismo" que consiste em uma das estratégias de captura. Diante do quase uníssono simplificador "O gigante acordou" em que foram transformadas as manifestações de 2013 pela ótica das "máquinas de expressão" da grande mídia, é necessária a busca de ferramentas para que se compreenda o fenômeno e, nesse sentido, o resgate da complexidade do acontecimento. Conforme debate proposto por Venício A. de Lima,

O desenvolvimento tecnológico e a conformação dos sistemas econômicos fizeram com que as sociedades se tornassem mais complexas e grande parte da população fosse, aos poucos, sendo

Disponível em: https://www.nucleodoconhecimento.com.br/comunicacao/midialivrismo-e- 
intermediada por tecnologias (mídias) e instituições (empresas privadas) que estão longe de ser meros condutores neutros por meio dos quais a informação circula livremente.

Hoje, essas empresas de mídia - que "falam" como se fossem representantes de cada um de nós - constituem-se, elas próprias, em importantes e poderosos atores, tanto econômicos quanto políticos, mas, sobretudo, como atores determinantes na construção da opinião pública em todo o mundo. (Lima, 2010, p. 103).

E essa construção da opinião pública pode ser notada pelo enquadramento reservado às manifestações brasileiras, sobretudo nos eventos entre os dias 13 e 20 de junho daquele ano, período em que praticamente desaparecem das coberturas da grande mídia depoimentos e entrevistas com pontos de vista conflitantes que possibilitassem ao receptor uma melhor avaliação dos acontecimentos. Período esse que consolida, pela inserção tautológica de uma demarcação, uma oposição dos corpos e mentes que estavam nas ruas: a grande maioria da multidão pacífica; um pequeno grupo infiltrado de mascarados, vândalos, baderneiros, arruaceiros. Raras não foram as circunstâncias em que esses rótulos foram empregados. Um desdobramento, meses após, cujas imagens, extensamente divulgadas, renderam à mídia corporativa vastos argumentos para reiterar essa demarcação: o episódio envolvendo o cinegrafista da TV Bandeirantes, Santiago llídio Andrade. Nesse sentido, a opinião do jornalista Josias de Souza, em artigo intitulado "Black blocs têm seu primeiro feito: um cadáver", oferece lastro a essa exposição.

Morreu o cinegrafista Santiago llídio Andrade, 49 anos. Trata-se daquele profissional que foi atingido na cabeça por um rojão vadio enquanto tentava filmar a enésima erupção de fúria da "minoria de vândalos" que se infiltra nas "manifestações pacíficas" para transformá-las em surtos de desordem. Eles finalmente obtiveram seu primeiro grande feito. Já dispõem de um cadáver.

Com seus protestos de inspiração anarquista, a estudantada de músculos inflados, de cara coberta e de índole violenta ainda não produziu a derrocada do capitalismo. Mas talvez consiga revolucionar a semântica dos protestos. As palavras agora devem ganhar novo sentido. "Minoria de vândalos"? É muito pouco! Black Blocs? O escambau! Eles são bandidos.

Disponível em: https://www.nucleodoconhecimento.com.br/comunicacao/midialivrismo-e- 
Supremo paradoxo: exaltados pela mídia do tipo Ninja como inimigos da ordem burguesa e das grandes corporações, os criminosos bemnascidos levaram ao túmulo um trabalhador. E graças às imagens captadas pelas lentes da velha mídia os selvagens mascarados que manusearam o rojão ganharam uma visibilidade que, por hedionda, desafia a ineficiência da polícia $[\ldots]^{[8]}$.

Essa disputa pelo assentimento da opinião pública por meio da representação do acontecimento, cuja atribuição de papéis aos agentes diversos decorre dentro de uma escala de valores, remete a um fundamento do interacionismo simbólico da Escola de Chicago, fundadora da reflexão sobre a comunicação, sobre o qual Francisco Rüdiger discorre, referindo-se à sociedade como uma estrutura simbólica criada pelo processo de comunicação - cujo espaço é palco de conflitos.

A comunicação cria e sustenta determinadas hierarquias simbólicas, em que se mantém um sistema de poder. [...] A comunicação é, portanto, um processo que pode servir para promover ou reprimir o conhecimento e a autodeterminação. A perspectiva pela qual se opta depende das estratégias dos participantes. As pessoas podem se conduzir no sentido de transformar comunicativamente sua estrutura simbólica ou de controlar a comunicação através dos simbolismos, conforme se posicionam perante a estrutura de poder vigente na sociedade. (Rüdiger, 2004, p. 45).

As máquinas de expressão - apontadas por Lazzarato como aparelhos de captura e controle da multiplicidade que, na trilha da revolução tecnológica digital confrontam com os novos meios que buscam as brechas necessárias para a tentativa de disrupção da diretiva hegemônica imposta pelos meios de comunicação institucionalizados - rivalizam com a insurgência em fluxo na tribuna social.

Exemplo desse procedimento se verifica em matéria do site de notícias e análises Diário do Centro do Mundo, intitulada "Santiago e as tragédias anunciadas nos protestos", sobre a morte do cinegrafista da TV Bandeirantes. Sem eximir de culpa parte dos manifestantes e a polícia pelos desdobramentos violentos dos protestos, o $D C M$ atribui à imprensa o seu quinhão.

A imprensa tem boa dose de culpa. Com suas coberturas parciais e repressoras, vem desde junho classificando a tudo e a todos como

Disponível em: https://www.nucleodoconhecimento.com.br/comunicacao/midialivrismo-e- 
"vândalos e vandalismo" e mostrando o reflexo no trânsito da cidade. Pouco importa a pauta e pertinência do protesto. Toda a cobertura sempre começa pelo final: "Terminou em quebradeira..." Nunca se noticia como nem porque começou. Os repórteres das grandes emissoras sofrem na pele a fúria da turba contra essa cobertura simplista e tendenciosa. Os editoriais de hoje em homenagem e de repúdio à morte de Santiago são tão óbvios quanto cínicos. ${ }^{[9]}$

A política da multiplicidade para as lutas do século XXI, que necessariamente passa pelo simbólico e pelo contágio, detectada por Lazzarato com o ciclo de Seattle, seguindo-se ao Fórum Social Mundial e mobilizando multidões globais contra a Guerra do Golfo, alcança paralelo nas manifestações de 2013 no Brasil. E cabe aos pesquisadores da Área de Comunicação, sob pena de perderem "o bonde do acontecimento", a atenção necessária para os processos emergentes, bem como para o contra-ataque dos poderes que se reorganizam. Lazzarato afirma o seguinte:

Todo mundo que chegou a Seattle com suas máquinas corporais e suas máquinas de expressão voltou para casa precisando redefinir estas máquinas a partir do que fizeram e disseram enquanto estavam lá. As formas de organização política (de co-funcionamento dos corpos) e as formas de enunciação (teorias e enunciados sobre o capitalismo, sobre os sujeitos revolucionários, formas de exploração) precisam ser medidas, reavaliadas, reinterpretadas à luz do acontecimento.

Até mesmo os trotskistas ficam obrigados a se questionar: o que aconteceu? O que acontece? O que ainda vai acontecer? Estão, daqui para a frente, são obrigados a se colocar sobre o que foram (a organização) e o que dizem (os seus discursos), diante do acontecimento.

É nesse momento que o acontecimento revela sua natureza problemática. Todos são levados a se abrir ao acontecimento, ou seja, ao plano das novas perguntas e das novas respostas. Aqueles que já trazem as respostas todas prontas (e eles são numerosos ... ) perdem 0 bonde do acontecimento. (Lazzarato, 2006, p. 23).

Essas considerações coadunam, por sua vez, com as inferências de Ivana Bentes ao analisar as manifestações brasileiras:

O que está em jogo afinal? \#ninjasomostodos, o midialivrismo e o midiativismo se encontram numa linguagem e experimentação que cria

Disponível em: https://www.nucleodoconhecimento.com.br/comunicacao/midialivrismo-e- 
outra partilha do sensível, experiência no fluxo e em fluxo, que inventa tempo e espaço, poética do descontrole e do acontecimento.

Exprimir o "grito", como escreveu Jacques Rancière, tanto quanto tomar posse da palavra é o modo de desestabilizar a partilha do sensível e produzir um deslocamento dos desejos e constituir o sujeito político multidão. Trata-se de política como comoção, catarse, mas também negociação e mediação.

Estamos vendo surgir nas ruas uma multidão capaz de se autogovernar a partir de ações e proposições policêntricas, distribuídas, atravessadas por poderes e potências muitas vezes em violento conflito, mas que constituem uma esfera pública em rede, autônoma em relação aos sistemas midiáticos e políticos tradicionais e que emergiu e se espalhou num processo de contaminação virótica e afetiva, instituindo e constituindo uma experiência inaugural do que poderíamos chamar das revoluções $\mathrm{P} 2 \mathrm{P}$ ou revoluções distribuídas, em que a heterogeneidade da multidão emerge em sinergia com os processos de auto-organização (autopoiesis) das redes. (Malini e Antoun, 2013, p. 15-16).

Algumas observações da autora, outrossim, remontam um dos aspectos de multidão definidos por Antonio Negri: “[...] é uma potência ontológica. Isto significa que a multidão encarna um dispositivo que procura representar o desejo e transformar o mundo. Melhor ainda: ela quer recriar o mundo à sua imagem e semelhança, ou seja, fazer dele um grande horizonte de subjetividades que se exprimem livremente e constituem uma comunidade de homens livres". (Negri, 2006, p. 130).

No entanto, como se trata de experiência "no fluxo e em fluxo" num palco de conflitos alicerçado por hierarquias simbólicas e sistemas de poder, "o logro da representação" opera no sentido de transformar em uno as multiplicidades. (lbid., p. 130).

\section{O FATO E A NARRAÇÃO}

Em A narração do fato: notas para uma teoria do acontecimento, Muniz Sodré disserta sobre a corporação jornalística "[...] que vem desfilando na história com o estandarte de defesa dos direitos civis, com foco na liberdade de expressão e na ideologia do esclarecimento, sempre escudado em estratégias discursivas de captação da escuta das massas". (Sodré, 2012, p. 15). O autor alerta para o jornalismo que, como

Disponível em: https://www.nucleodoconhecimento.com.br/comunicacao/midialivrismo-e- 
processo comunicativo amplo, que mobiliza diferentes tipos de discurso, faz esquecer os procedimentos retóricos e imaginosos, na construção do acontecimento, sob o que parece ser apenas informação, pura e simples, sob a forma de notícia.

Não se trata de manipulações deliberadas, nem de mentiras, mas de interpretações que podem muitas vezes lançar mão de recursos típicos da ficção literária, com vistas à criação de uma atmosfera semântica mais compreensiva. Apesar de sua aposta histórica no esclarecimento neutro, a notícia não prescinde, em termos absolutos, do apelo à carga emocional contida nos estereótipos que derivam das ficcionalizações ou dos resíduos míticos. (lbid., p. 15-16).

Exemplos recentes possibilitam a investigação desse efeito de objetividade na organização do discurso que, em última instância, reflete a visão de mundo projetada por interesses institucionais. É o caso da visão adotada em determinado momento da cobertura das manifestações de 2013 , no que se referia ao comportamento dos "vândalos, bárbaros, agitadores" que se infiltravam nas manifestações "pacíficas e legítimas da verdadeira população brasileira".

$\mathrm{Na}$ esteira tautológica dos meios de comunicação, que se integram, redirecionam-se, normas de comportamento são segredadas. Capturadas as causas prementes da realidade, e difundidas pelos meios, tornam-se o referente institucional com o qual, por intermédio de estratégias de significação, institui-se a relação de empatia com a multidão. A evocação para uma atitude positiva, "protestar sob normas de civilidade", sob o discurso da convivência pacífica, é recurso recorrente nas coberturas jornalísticas sobre assuntos dessa natureza (liberdade de expressão ou degenerescência de uma causa?); não raro a polêmica é escamoteada para o discurso asséptico do especialista. A imagem (re)contextualizada. Os números, positivamente apresentados. Factuais. Objetivos. Sem objeções. As diferenças aplainadas. Fala o jornalista, o sociólogo, o legislador.

Sobre essa "circulação circular da informação" (veículos de comunicação que se pautam, capitaneados pela televisão), Pierre Bourdieu afirma que "Para romper o círculo, é preciso proceder por transgressão, mas a transgressão não pode ser senão através da mídia; é preciso conseguir produzir um 'choque"'. (Bourdieu, 1997, p.35).

Disponível em: https://www.nucleodoconhecimento.com.br/comunicacao/midialivrismo-e- 
Em termos estruturais, a solução proposta por Bourdieu corrobora elementos da teoria de Hans Magnus Enzensberger, que defende, já no início dos anos 1970, a potencialidade de emancipação dos meios eletrônicos devido a sua estrutura coletiva. "Em sua estrutura, as novas mídias são igualitárias. Por meio de um simples processo de conexão, todos podem participar delas". (Enzensberger, 2003, p. 39).

Enzensberger discorre sobre as possibilidades objetivamente subversivas das mídias eletrônicas, que, de certa maneira, se materializam na disponibilidade dos novos meios virtuais nesse início do século XXI: "O potencial mobilizante direto das mídias é ainda mais evidente quando usado de forma conscientemente subversiva. [...] Apenas grupos ativos e coerentes podem impor às mídias a lei de sua forma de agir". (Ibid., p. 71). Ativos e coerentes: nessa adjetivação necessária é que devem agir os efeitos neutralizadores do discurso das mídias corporativas.

Também sobre choque, choques perceptivos que transformam os imaginários, teoriza Juremir Machado da Silva, para quem "Sem intensificação do ruído não há choque perceptivo, nem transformação dos imaginários. O pesquisador necessita, mais do que tudo, localizar e descrever esses choques de percepção que desviam o olhar". (Hohlfeldt e Gobbi, 2004, p. 330).

\section{POR UMA SOCIOLOGIA DO JORNALISMO}

Uma ancoragem na Sociologia do jornalismo oferece embasamento teórico auxiliar na desmistificação do jornalismo como um defensor da democracia, por relativizar o poder dos jornalistas, tendo como premissa que estes se inserem em um contexto institucional cujos interesses não se desvinculam dos campos econômico e político. Nessa vertente, Érik Neveu defende que uma sociologia do jornalismo deve se confrontar também com a dimensão política de seu objeto. E aqui se impõe a temática do quarto poder que, segundo afirma, pode se revelar simplista. "Evocar um quarto poder (que se soma ao executivo, ao legislativo e ao judiciário) consagra uma visão ingênua dos poderes sociais na qual não figuram os interesses econômicos e os grupos de pressão". (NEVEU, 2006, p. 196). Por essa abordagem, tal temática oferece 
uma ampliação do conceito encontrado em Paul Virilio: “[...] única de nossas instituições capaz de funcionar fora de qualquer controle democrático eficaz, já que toda crítica independente dirigida contra ele, toda solução alternativa, permanecem desconhecidas do grande público [...]”. (Virilio, 1996, p.11).

Neveu escreve que, para se levar a sério a ideia do jornalismo como instituição de democracia, devem-se constatar os aportes da análise sociológica, e, igualmente, explicitar os a priori normativos.

O postulado normativo que associa o jornalismo à ideia de democracia pode se condensar num silogismo. Uma sociedade política não é feita de consumidores, mas de cidadãos. A cidadania consiste em tomar parte num debate permanente, pontuado por momentos de participação, sobre as questões do viver em comum e suas soluções. Esse papel de cidadão precisa de uma informação inteligível, completa e contraditória que dê sentido a um máximo de dimensões da vida social e, portanto, não se polarize sobre os únicos discursos da instituição, não identifique as vias ordinárias do trivial ou do subalterno, não reduza a sociedade a seus extremos. (lbid., p.196).

A observação de Neveu remete ao embate entre o "plurilinguismo" e o "monolinguismo", entendidos como duas formas diferentes de pensar e de agir na expressão de uma mesma língua ou de um mesmo regime de signos, conceitos presentes na obra As revoluções do capitalismo ${ }^{[10]}$, de Maurizio Lazzarato.

Se esses a priori normativos são aceitos, a concepção do jornalismo e da imprensa como uma atividade econômica entre outras e a visão das audiências como coleções de consumidores constituem obstáculos à realização de uma missão democrática do jornalismo. Que as publicações ou editoriais se dirijam a públicos consumidores não constitui em si um perigo (mesmo os sociólogos podem ficar contentes de utilizá-las por hobby ou lazer). Mas o ideal democrático requer um jornalismo de informação econômica e culturalmente acessível a todos, produtor de reflexão sobre as questões políticas. (Ibid., p.196).

Sobre o poder dos jornalistas, no entanto, Neveu, problematiza da seguinte forma:

Não se trata, então, de negar a realidade de um poder, mas de estar sensível a seus paradoxos. O primeiro está ligado a uma dimensão da crença. Apesar dos efeitos frequentemente mal mensuráveis, o poder 
das mídias é também o de valorizar uma crença na sua influência, que Ihe faz atribuir resultados imaginários. Está ligado também à natureza de uma influência que se expressa mais numa capacidade de definir um horizonte de debates e de questões que num controle orwelliano dos espíritos. A noção de construção social da realidade vem sendo mal aplicada. Ela permanece, contudo, pertinente quando sugere um processo de seleção e de hierarquização dos fatos e assuntos cujas causas e regularidades uma análise empírica do trabalho jornalístico pode resgatar. (Ibid., p.141).

Essa definição de um horizonte de debates, ainda que de certa maneira periférica, vem continuamente digladiada pelas pautas acionadas nos novos espaços reclamados pelo midialivrismo. Destarte, "sendo o jornalismo inseparável das mídias nas quais ele se desenvolve, é também com as mitologias da comunicação contraditórias e confusas - que se confronta todo trabalho sobre o jornalismo". (Ibid., p.15).

Ante a relativização da ideia desse ofício como instituição de democracia, a necessária apresentação do contraditório encontra eco nas considerações do fundador e diretor editorial do site de notícias e análises Diário do centro do Mundo, Paulo Nogueira, "[...] Os donos escolhem cuidadosamente o que dar e o que não dar em seus jornais, revistas, rádios, telejornais. E isso é claramente transmitido para editores, comentaristas, colunistas". [... $]^{[11]}$, escreveu após a saída de Dilma Rousseff do cargo da presidência da República e a com chegada do vice, Michel Temer, ao poder, numa análise em matéria intitulada "Como vai ser o noticiário da mídia plutocrática daqui por diante" que, segundo afirmava, àquela altura se esforçaria na forja de notícias positivas para a legitimação do novo comando, o jornalista chamava a atenção para o embate de narrativas que, dentre idas e vindas, a partir dali se estabeleceria.

\section{CONSIDERAÇÕES FINAIS}

O advento de dispositivos móveis e o uso das redes sociais tanto para a organização como para a comunicação dos grupos durante o acontecimento, como por exemplo nas brasileiras "Jornadas de junho", que levaram centenas de milhares de

Disponível em: https://www.nucleodoconhecimento.com.br/comunicacao/midialivrismo-e- 
manifestantes às ruas, movidos por reivindicações distintas, oferecem profícuo pano de fundo para pesquisas que, pela complexificação do cenário que se delineia, poderão contribuir para os estudos comunicacionais em uma era notadamente marcada pela urgência e confluência de diferentes formatos mediáticos. Diferentes narrativas.

Para tanto, uma cartografia da crítica oferecida por esses veículos à atuação da grande mídia brasileira possibilita o escrutínio de diferentes enquadramentos, uma vez que os sites independentes - sob a proposta de uma circulação livre e cooperativa de seus conteúdos - midialivristas não só oferecem o contraponto das notícias apresentadas pelos veículos tradicionais, bem como, em uma crítica quotidiana, exercem a tarefa de descortinar os bastidores dessas notícias, aclarando para 0 público os interesses por detrás das escolhas nas coberturas realizadas por estes meios.

O trajeto das reivindicações, concretizadas pelas manifestações de rua, desde 2013 até culminarem nos desdobramentos de 2016 (sem que se descarte, evidentemente, os acontecimentos decorrentes), nas diferentes abordagens oferecidas de lado a lado, tanto pelos meios hegemônicos quanto pelos sites independentes, seja mediante 0 excesso de exposição ou nos propositais apagamentos, consiste tema de interesse na investigação do campo comunicacional, uma vez que oferece visões que disputam a cooptação, ou a reelaboração, da opinião pública.

Diante da construção de novas narrativas e da reorganização das narrativas vigentes e, ainda, com a dinâmica dos sites independentes, que irradiam seus conteúdos de maneira cooperativa, faz-se necessária a verificação da potencialidade de contrainformação que o midialivrismo pode operar frente ao discurso das mídias tradicionais.

\section{REFERÊNCIAS}

BOURDIEU, Pierre. Sobre a televisão. Tradução, Maria Lúcia Machado - Rio de Janeiro: Jorge Zahar Ed. 1997. 
ENZENSBERGER, Hans Magnus. Elementos para uma teoria dos meios de comunicação. Tradução Cláudia S. Dombusch. São Paulo : Conrad Editora do Brasil, 2003.

HOHLFELDT, Antonio. GOBBI, Maria Cristina (Orgs.). Teoria da comunicação : antologia de pesquisadores brasileiros. - Porto Alegre: Sulina, 2004.

LAZZARATO, Maurizio. As revoluções do capitalismo. Tradução de Leonora Corsini. Rio de Janeiro: Civilização Brasileira, 2006.

LIMA, Venício A. de. Liberdade de expressão x Liberdade de imprensa: Direito à comunicação e democracia. São Paulo : Publisher Brasil, 2010.

MALINI, Fábio. ANTOUN, Henrique. A internet e a rua: ciberativismo e mobilização nas redes sociais. Porto Alegre: Sulina, 2013.

NEGRI, Antonio. De volta [entrevistas a Anne Dufourmantelle]; tradução Clóvis Marques - Rio de Janeiro: Record, 2006.

NEVEU, Érik. Sociologia do jornalismo / Erik Neveu; Tradução Daniela Dariano. São Paulo: Loyola, 2006.

RÜDIGER, Francisco. Introdução à teoria da comunicação: problemas, correntes e autores. 2. ed. São Paulo: Edicon, 2004.

SODRÉ, Muniz. A narração do fato : notas para uma teoria do acontecimento. 2. ed. - Petrópolis, RJ : Vozes, 2012.

VIRILIO, Paul. A arte do motor / Paul Virilio ; tradução Paulo Roberto Pires. - São Paulo : Estação Liberdade, 1996.

\section{SITES CONSULTADOS}

http://www.baraodeitarare.org.br/ 
www.observatoriodaimprensa.com.br

https://ninja.oximity.com/

http://www.revistaforum.com.br/

https://theintercept.com

http://www.uol.com.br/

\section{APÊNDICE - REFERÊNCIAS DE NOTA DE RODAPÉ}

3. Leia-se por grande mídia os veículos de comunicação pertencentes aos principais grupos de comunicação do país, compostos, sobretudo, pelos jornais $O$ Globo, Folha de S. Paulo, O Estado de S. Paulo e os canais de TV Globonews e Rede Globo, dada a sua abrangência e preponderância na formação de opinião pública. A contrapartida é estabelecida por sites independentes que emergem com o conceito de mídia livre e colaborativa, cujos conteúdos se pautam e têm trânsito entre si e dialogam com conteúdos de publicações de empresas jornalísticas que se desvinculam da visão hegemônica, com destaque para os sites de notícias e análises Diário do Centro do Mundo (DCM), The Intercept Brasil, Jornal GGN e Conversa afiada, por serem meios que se firmaram com considerável número de acessos e que possuem à frente jornalistas egressos da grande mídia.

4.

Disponível

em:

http://www.observatoriodaimprensa.com.br/news/view/o_linchamento_da_midia_ninj a Acesso em 22/10/2013.

5. Acrônimo de Narrativas Independentes, Jornalismo e Ação, que ganhou relevância na cobertura e transmissão de vídeos ao vivo e sem cortes dos protestos.

6. Disponível em: https://www.pragmatismopolitico.com.br/2013/08/por-que-a-midiatradicional-tem-medo-da-midia-ninja.html Acesso em 14/06/2019. 
7. Disponível em: https://www1.folha.uol.com.br/poder/2013/12/1390207manifestacoes-nao-foram-pelos-20-centavos.shtml Acesso em: 14/06/2019.

8. Disponível em: http://josiasdesouza.blogosfera.uol.com.br/2014/02/10/black-blocstem-seu-primeiro-feito-um-cadaver/ Acesso em: 10/02/2014.

9. Disponível em: https://www.diariodocentrodomundo.com.br/santiago-e-astragedias-anunciadas-nos-protestos/ Acesso em: 14/04/2019.

10. Segundo Bakhtin, a criação diferencial de agenciamentos de enunciação é animada pelas forças sociais políticas que visam à polifonia e à criação de novas possibilidades semânticas, que ele chama "plurilinguismo". Ao contrário, as práticas da informação e da comunicação são constituídas por forças que visam à unificação, à centralização, à homogeneidade das falas, das línguas, das semióticas, processo que ele denomina "monolinguismo". (LAZZARATO, 2006, p.157).

11. Disponível em: https://www.diariodocentrodomundo.com.br/como-vai-ser-onoticiario-da-midia-plutocratica-daqui-por-diante-por-paulo-nogueira/ Acesso em: 12/05/2016.

Enviado: Outubro, 2019.

Aprovado: Outubro, 2019. 